\title{
SYNTHESIS, SPECTRAL CHARACTERIZATION, AND BIOLOGICAL ACTIVITIES OF COBALT(II) COMPLEXES OF SCHIFF BASES DERIVED FROM $O$-VANILLIN AND $P$-VANILLIN WITH 3-AMINOPYRIDINE
}

\author{
${ }^{a *}$ Shaibu, Rafiu O and ${ }^{b}$ Watkins, Gareth M \\ $a^{a^{*}}$ Department of Chemistry, University of Lagos \\ ${ }^{\mathrm{b}}$ Department of Chemistry, Rhodes University, Eastern Cape, South Africa. \\ (Corresponding Author Email: rshaibu@unilag.edu.ng) \\ (Received: $1^{\text {st }}$ September, 2018; Accepted: $16^{\text {th }}$ November, 2018)
}

\author{
Highlights \\ - Two 3-aminopyridine derived Schiff bases were synthesized. \\ - Six cobalt (II) complexes of the Schiff bases were synthesized. \\ - The Schiff bases and the cobalt (II) complexes were characterized. \\ - Antimicrobial and brine shrimps activities of the complexes and the Schiff bases were examined
}

\section{ABSTRACT}

\begin{abstract}
Two biologically active Schiff base GL1 and GL2 were synthesized in equimolar reaction of 3-aminopyridine with $o$-vanillin and $p$-vanillin. The synthesized Schiff bases were reacted with cobalt acetate, cobalt chloride or cobalt chloride with trimethylamine by using a molar ratio of Schiff base: cobalt salt as 2:1. The characterization of Schiff bases and cobalt complexes was done by UV-visible in methanol, diffused reflectance, FTIR (mid and far), mass spectrometry studies while ${ }^{1} \mathrm{H}$ NMR and ${ }^{13} \mathrm{C}$ NMR were used to further characterize the Schiff bases. The FTIR results confirmed the bidentate binding of the Schiff bases with cobalt center after the formation of the complexes. The UV-visible spectra and diffused reflectance spectra data obtained were used to further investigate the electronic structure as well as the properties of Schiff bases and their cobalt complexes. On the basis of the spectral studies, distorted tetrahedral geometry has been assigned for the Co(II) complexes. The antimicrobial activities of the two Schiff bases GL1, GL2 and their cobalt(II) complexes were tested against laboratory isolated Staphylococcus aureus, Pseudomonas aeruginosa, Escherichia coli and one fungus strain, Aspergillus niger. The antimicrobial evaluation demonstrates significant activity of the Schiff bases and the cobalt complexes against the four known human pathogens. The brine shrimps lethality study confirmed that the compounds are concentration and geometry dependent. The studies showed the complexes were higher in biological activity than the corresponding Schiff bases.
\end{abstract}

Keywords: 3 -aminopyridine Schiff bases, cobalt(II), antimicrobial activity, brine shrimps test

\section{INTRODUCTION}

The widespread and continuous existence of antibiotic-resistant microorganism is a major worldwide problem. This has given rise to several innovative researches for antibiotic drug discovery. The quest to produce antibiotic drugs to combat drug resisting microbes has led to the considerable attention received by Schiff bases and their transition metal complexes. They are known to have simple synthetic methods and have effective biological importance as a result of their diverse pharmacological properties (Saxena, 1987; Williams, 1972; Furst, 1963). A number of in vivo studies surveyed, have indicated that biologically active compounds usually contain heteroatoms and become more bacteriostatic and carcinostatic upon chelation (Jain, Jain and Pitre, 2002; Hania, 2009).
The heteroatoms- nitrogen, oxygen and sulphurare significant in the coordination of metals. They serve at the active sites of numerous metallobiomolecules. Cobalt, copper and nickel are known to have great affinity for coordination to the heteroatoms because of small size and high nuclear charge. For instance, tetradentate Schiff bases with a $\mathrm{N}_{2} \mathrm{O}_{2}$ donor atom set are well-known to form complexes with various metal ions (Atkins et al., 1985; Boucher \& Coe, 1976; Yuan Ruo, Chai Ya-Qin, Liu Dong, Gao De, Li Jun-Zhong, 1993). Many complexes with $\mathrm{N}_{2} \mathrm{O}_{2}$ donor atom, have proven antitumor, antibacterial, antifungal, antiviral properties (Cui, Dong, Li, Li \& Chen, 2012; Gurumoorthy, Mahendiran, Parbhu, Arulvasu \& Rahiman, 2014; Bhattacharyya, Sen, Harms \& Chattopadhyay, 2015). The synthesis of Schiff bases and their metal complexes has led to 
increase in the development of the field of bioinorganic and coordination chemistry. It is long known that many of these complexes serve as models for biologically important species. Consequently, many studies have been carried out to examine their geometry and the biological properties of the Schiff bases and metal complexes. Coordination complexes of substituted salicylaldehyde Schiff bases are known to have shown diverse structures with a wide range of bonding interactions, electronic as well as biological properties (Soliman \& Linert, 1999; Zolezzi, Decinti \& Spodine, 1999; Elmali, Zeyrek, Elerman \& Durlu, 2000; Hegazy and Gaafar, 2012).

In this paper, we report the synthesis of Schiff bases derived from the condensation reaction of 3 -aminopyridine with $o$-vanillin or $p$-vanillin. The isolated Schiff bases were reacted with cobalt acetate, cobalt chloride or cobalt chloride with trimethylamine to form cobalt(II) complexes. The Schiff bases and their corresponding cobalt(II) complexes were investigated for in vitro antimicrobial activity against three well known bacteria and a fungus. Their cytotoxicity effects on brine shrimps were also examined. The results obtained from the characterization and the biological activities were used to confirm the effect of variation of the size and nature of the substituents on the coordination geometry around the metal ion, electronic and their biological properties.

\section{Experimental}

\section{Materials and methods}

The 3-aminopyridine, o-vanillin, p-vanillin were purchased from Sigma-Aldrich. Cobalt acetate and cobalt chloride purchased from E. Merck were used without further purification.

\section{Physicochemical Measurements}

Mid infrared spectra were recorded on a PerkinElmer spectrum 2000 FT-IR spectrometer. The spectra were determined using a KBr beam splitter and a DTG detector, in the region $4000-400 \mathrm{~cm}^{-1}$ with typically 16 scans at an average resolution of
$4 \mathrm{~cm}^{-1}$. Samples were run as mulls in Nujol on $\mathrm{KBr}$ windows. Far infrared spectra were recorded on a Perkin-Elmer spectrum 2000 FT-IR spectrometer. The spectra were recorded in the region $650-100 \mathrm{~cm}^{-1}$ with typically 64 scans and at an average resolution of $12 \mathrm{~cm}^{-1}$. Samples were run as mulls in Nujol on polyethylene windows. Carbon, hydrogen and nitrogen combustion microanalyses were carried out using a Fisons Elemental Analyzer 1108 CHNS-O. Melting points were determined using a Gallenkamp melting point apparatus. The results were uncorrected. The ultraviolet-visible (UV-vis) spectra were recorded on a Varian Cary 500 spectrophotometer. The electronic properties were examined in methanol. The near-infraredvisible (NIR-VIS) spectra were carried out using a digital Cary 500 (Varian) spectrophotometer. All the measurements were made at room temperature. The NIR-VIS and UV-vis spectra data were employed for the analysis of the Schiff bases and the complexes. The diffuse reflectance spectra of the isolated Schiff bases and the complexes were measured by using a Cary 500 UV-vis/NIS spectrometer fitted with a Cary diffuse reflectance accessory. The spectra were collected as $\%$ reflectance at a spectra bandwidth of $2 \mathrm{~nm}$ and at a rate of $200 \mathrm{~nm} /$ min between 200 $-800 \mathrm{~nm}$ for UV-vis measurement and $700-2000$ $\mathrm{nm}$ for visible-near infrared (Vis-NIR) region.. Polytetrafluoroethylene (PTFE) powered was used as background. The spectra have been smoothened and derivatized by using the SavitskyGolay method employing 45 and 55 convolution points for UV-vis and vis - NIR respectively. The spectra were then converted to absorbance for comparison with solution spectra. The Schiff bases and their corresponding cobalt complexes were analysed for their purity by microanalysis and IR spectra. Cobalt analyses was done using inductively coupled plasma (ICP). ${ }^{1} \mathrm{H}$ NMR and ${ }^{13} \mathrm{C}$ NMR spectra of Schiff base GL1 and GL2 were recorded on an Avance Bruker AMX 400 $\mathrm{MHz}$ spectrometer using deuterated chloroform as solvent and tetramethylsilane (TMS) as the internal reference. All spectra were recorded at ambient temperature. Chemical shifts were measured in parts per million (ppm) downfield of 
the reference signal.

\section{BIOLOGICAL ACTIVITY}

Preparation of microbial cultures (Antibacterial susceptibility screening, inoculation and incubation)

The antibacterial activities of Schiff bases GL1 and GL2 and their cobalt (II) complexes were tested against laboratory isolated Staphylococcus aureus, Pseudomonas aeruginosa, Escherichia coli and one fungus strain, Aspergillus niger, using the disc diffusion method (Madigan, Martinko \& Parker, 1998). The microorganisms were supplied by the Microbiology Department, Rhodes University, South A frica. Nutrient agar and broth, malt extracts were supplied by Biolab. Antibiotic assay discs, $12.7 \mathrm{~mm}$ diameter and sterile $0.45 \mu \mathrm{m}$ membrane filters were purchased directly from Sigma-Aldrich.

Nutrient agar for bacteria and malt extract agar for the fungus were separately inoculated with the isolated microorganisms (Ernst and Rogers, 2005). $4 \mathrm{mg} / \mathrm{ml}, 1 \mathrm{mg} / \mathrm{ml}$ and $0.5 \mathrm{mg} / \mathrm{ml}$ of the synthesized Schiff bases and their cobalt complexes were dissolved in methanol and absorbed on the $12.7 \mathrm{~mm}$ diameter antibiotic disc paper and were placed firmly on the agar media. The plates were incubated at $32{ }^{\circ} \mathrm{C}$ for bacteria 18-24 hours and at $37^{\circ} \mathrm{C}$ for fungus for $10-14$ hours. The soaked antibiotic assay discs were air dried under a lamina flow hood and placed on each of the inoculated malt extracts plates with the help of forceps flamed from time to time. All the procedures highlighted above were done aseptically under a lamina flow hood. After incubation, the resulting inhibition zones on the plates were measured. The diameters of inhibition zones around the discs were measured to the nearest $\mathrm{mm}$, the average diameter was recorded and compared to that of the control. The control samples were absorbed in methanol only. The data reported in Table 5 are averages of three experiments.

\section{Bioassay (Brine shrimp lethality test)}

The assay method described by Anderson et al., with minor modifications was used for the lethality test of the Schiff bases and their cobalt complexes (Anderson, Goezt \& McLaughlin, 1991). Brine shrimp (Artemia salina leach) eggs were hatched in a shallow rectangular plastic dish $(22 \times 32 \mathrm{~cm})$, filled with artificial seawater and used after 48 hours. A $100 \mu \mathrm{L}$ of sea water containing 10-13 Artemia nauplii was added to micro-well containing $150 \mu \mathrm{L}$, giving a final volume of $250 \mu \mathrm{L}$ per well with test solutions at concentrations 400 , 200, 100 and $50 \mu \mathrm{L} / \mathrm{mL}$. The micro well plates were covered and left in a dark cupboard for observation after 24 hours. Each well was examined under a Leica dissecting microscope and the numbers of dead (non-motile) as well as live nauplii were counted. The percent death at each dose was determined. $100 \mu \mathrm{L}$ of methanol was added to live larvae and the total number of larvae per well counted. The $\mathrm{LD}_{50}$ and $95 \%$ confidence were determined using probit analysis method described by Finney (Finney, 1971). 'R' data analysis computer program was used to analyzed the numerical data generated from the brine shrimps assay and to address the problems of disparity (RData, 2000).

\section{Procedure for the synthesis of Schiff bases GL1}

Equimolar quantities $(0.76 \mathrm{~g}, 5 \mathrm{mmol})$ of $p$ vanillin in $5 \mathrm{ml}$ ethanol was added to $(0.471 \mathrm{~g}, 5$ mmol) 3-aminopyridine in $5 \mathrm{ml}$ ethanol and refluxed for 1 hour. After cooling, the crystalline product was filtered and recrystallized from ethanol, and then dried under reduced pressure over silica. The reaction for the synthesis of GL1 is shown in Scheme 1.

\section{Procedure for the synthesis of Schiffbases GL2}

Equimolar quantities $(0.76 \mathrm{~g}, 5 \mathrm{mmol})$ of $o$ vanillin in $5 \mathrm{ml}$ ethanol was added to $(0.471 \mathrm{~g}, 5$ mmol) 3-aminopyridine in $5 \mathrm{ml}$ ethanol and refluxed for 1 hour. After cooling, the crystalline product was filtered and recrystallized from ethanol, and then dried under reduced pressure over silica.

Syntheses of Cobalt(II) complexes of GL1B and GL2B

To an ethanolic solution (5 $\mathrm{ml})$ of 3aminopyridine $(0.471 \mathrm{~g}, 5 \mathrm{mmol})$ was added $5 \mathrm{ml}$ of ethanolic solution of $p$-vanillin or $o$-vanillin 
$(0.76 \mathrm{~g}, 5 \mathrm{mmol})$. The mixture was refluxed in a round bottom flask. After refluxing for 1 hour, the solution was allowed to cool at room temperature. A methanolic solution $(5 \mathrm{ml})$ of cobalt acetate $(0.6226 \mathrm{~g}, 2.5 \mathrm{mmol})$ was added to the ethanolic solution of the GL1 and GL2 respectively and the mixture was further refluxed for another 1 hour. The mixture was allowed to form precipitate. The precipitate was filtered, washed with diethyl ether, and cold methanol. The

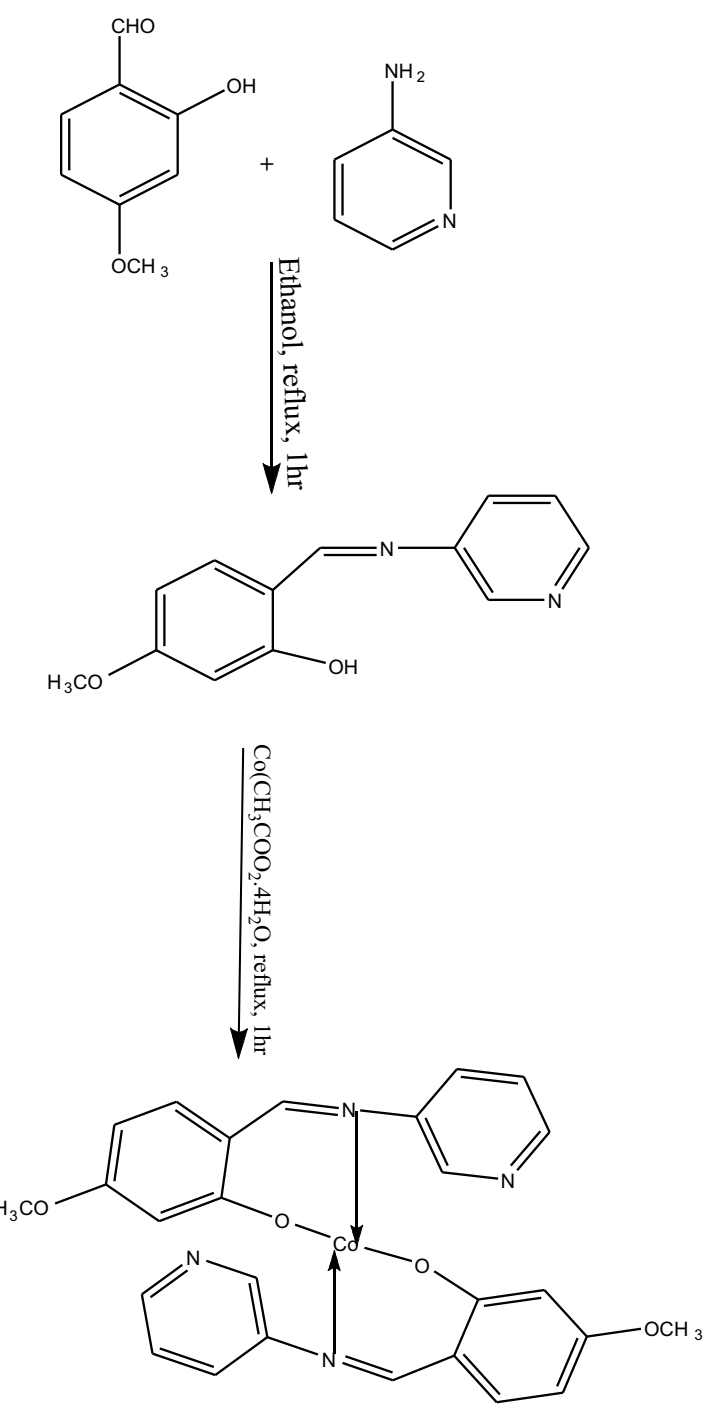

Scheme 1: Reaction pathways for obtaining GL1 Schiff bases and one of its proposed complexes.

\section{Syntheses of GL1A and GL2A complexes from cobalt(II) salts}

A methanolic solution $(10 \mathrm{ml})$ of cobalt chloride $\left(\mathrm{CoCl}_{2} .6 \mathrm{H}_{2} \mathrm{O}\right),(0.5948 \mathrm{~g}, 2.5 \mathrm{mmol})$ was added to $5 \mathrm{mmol}$ of each of the $(10 \mathrm{ml})$ GL1 and GL2 solution. The mixture was refluxed in a $100 \mathrm{ml}$ round bottom flask for 2 hours. The complex was allowed to precipitate. The precipitate was filtered, washed with diethyl ether, dried in the oven at 50 degree celcius and kept dry for analyses.

\section{Syntheses of GL1C and GL2C complexes from cobalt(II) salts}

To a solution of 3-aminopyridine (0.471 g, 5 $\mathrm{mmol})$ in tetrahydrofuran $(10 \mathrm{ml})$ was added $p$ vanillin $(0.76 \mathrm{~g}, 5 \mathrm{mmol})$ or $o$-vanillin $(0.76 \mathrm{~g}, 5$ $\mathrm{mmol}$ ) and refluxed for 30 minutes. The mixture cooled, and filtered. The mixture of trimethylamine $(0.6969 \mathrm{ml}, 5 \mathrm{mmol})$ and cobalt chloride $\left(\mathrm{CoCl}_{2} .6 \mathrm{H}_{2} \mathrm{O}, 0.5948 \mathrm{~g}, 2.5 \mathrm{mmol}\right)$ in methanol was added to the filtered Schiff base 
GL1 and GL2 solution respectively. The mixture was refluxed for another 1 hour. The solution was allowed to cool to room temperature. The precipitate obtained was filtered, washed with diethyl ether, cold methanol and dried over silica gel under reduced pressure.

\section{RESULTS AND DISCUSSION}

The physicochemical data for the Schiff bases GL1, GL2 and their corresponding cobalt complexes are listed in Tables 1 and 2 respectively. The two Schiff bases were obtain in good yield from the 1:1 $o$-vanillin or $p$-vanillin with 3aminopyridine. The resulting solids are intensely coloured, and stable in air. They are soluble in most organic solvents, but poorly soluble in water.

Table 1: Microanalysis and analytical data for the 3-aminopyridine-based Schiff bases GL1 and GL2

\begin{tabular}{|c|c|c|c|c|c|c|c|c|c|}
\hline \multirow{2}{*}{ No. } & \multirow{2}{*}{ Molecular formula } & \multicolumn{3}{|c|}{$\%$ Found (Calculated) } & \multirow{2}{*}{ Color } & \multirow{2}{*}{$\begin{array}{c}\text { Yield } \\
(\%)\end{array}$} & \multirow{2}{*}{$\begin{array}{l}\text { M.p. } \\
\left({ }^{\circ} \mathrm{C}\right)\end{array}$} & \multirow{2}{*}{$\begin{array}{c}\text { Molar } \\
\text { mass }\end{array}$} & \multirow{2}{*}{$\mathrm{M}+$} \\
\hline & & $\% \mathrm{C}$ & $\% \mathrm{H}$ & $\% \mathrm{~N}$ & & & & & \\
\hline GL1 & $\mathrm{C}_{13} \mathrm{H}_{12} \mathrm{~N}_{2} \mathrm{O}_{2}$ & $\begin{array}{c}67.93 \\
(68.41)\end{array}$ & $\begin{array}{c}5.23 \\
(5.30)\end{array}$ & $\begin{array}{c}12.05 \\
(12.27)\end{array}$ & yellow & 67 & $114-5$ & 228 & 228 \\
\hline GL2 & $\mathrm{C}_{13} \mathrm{H}_{12} \mathrm{~N}_{2} \mathrm{O}_{2}$ & $\begin{array}{c}67.57 \\
(68.41)\end{array}$ & $\begin{array}{c}5.28 \\
(5.30)\end{array}$ & $\begin{array}{c}11.94 \\
(12.27)\end{array}$ & orange & 75 & $119-20$ & 228 & 228 \\
\hline
\end{tabular}

Table 2: Microanalysis and analytical data for the cobalt complexes of GL1, GL2.

\begin{tabular}{|c|c|c|c|c|c|c|c|c|c|}
\hline \multirow{2}{*}{ No. } & \multirow{2}{*}{ Molecular formula } & \multirow{2}{*}{$\begin{array}{c}\text { Molar } \\
\text { mass }\end{array}$} & \multicolumn{4}{|c|}{$\%$ Found (Calculated) } & \multirow{2}{*}{ Color } & \multirow{2}{*}{ Yield (\%) } & \multirow{2}{*}{$\begin{array}{l}\text { M.p. } \\
\left({ }^{\circ} \mathrm{C}\right)\end{array}$} \\
\hline & & & $\% \mathrm{C}$ & $\% \mathrm{H}$ & $\% \mathrm{~N}$ & $\% \mathrm{Co}$ & & & \\
\hline GL1A & $\mathrm{C}_{26} \mathrm{H}_{26} \mathrm{ClCoN}_{4} \mathrm{O}_{5}$ & 568.9 & $\begin{array}{c}55.08 \\
(54.89)\end{array}$ & $\begin{array}{c}4.06 \\
(4.61)\end{array}$ & $\begin{array}{c}9.95 \\
(9.85)\end{array}$ & $\begin{array}{c}10.29 \\
(10.36)\end{array}$ & Green & 66 & $181-2$ \\
\hline GL1B & $\mathrm{C}_{26} \mathrm{H}_{22} \mathrm{CoN}_{4} \mathrm{O}_{4}$ & 522.4 & $\begin{array}{c}59.26 \\
(59.78)\end{array}$ & $\begin{array}{c}4.16 \\
(4.25)\end{array}$ & $\begin{array}{c}10.53 \\
(10.72)\end{array}$ & $\begin{array}{c}11.36 \\
(11.28)\end{array}$ & $\begin{array}{l}\text { greenish } \\
\text { yellow }\end{array}$ & 84 & $316-8$ \\
\hline GL1C & $\mathrm{C}_{26} \mathrm{H}_{30} \mathrm{CoN}_{4} \mathrm{O}_{7}$ & 569.5 & $\begin{array}{c}54.72 \\
(55.03)\end{array}$ & $\begin{array}{c}4.47 \\
(4.97)\end{array}$ & $\begin{array}{l}9.19 \\
(9.84)\end{array}$ & $\begin{array}{c}10.47 \\
(10.35)\end{array}$ & $\begin{array}{l}\text { greenish } \\
\text { yellow }\end{array}$ & 87 & $316-8$ \\
\hline GL2A & $\mathrm{C}_{26} \mathrm{H}_{26} \mathrm{ClCoN}_{4} \mathrm{O}_{6}$ & 584.9 & $\begin{array}{c}53.72 \\
(53.39)\end{array}$ & $\begin{array}{c}4.87 \\
(4.48)\end{array}$ & $\begin{array}{c}9.51 \\
(9.58)\end{array}$ & $\begin{array}{c}10.37 \\
(10.08)\end{array}$ & leaf green & 66 & $181-2$ \\
\hline GL2B & $\mathrm{C}_{26} \mathrm{H}_{23} \mathrm{CoN}_{4} \mathrm{O}_{4}$ & 522.4 & $\begin{array}{c}59.52 \\
(59.78)\end{array}$ & $\begin{array}{c}4.11 \\
(4.25)\end{array}$ & $\begin{array}{c}10.74 \\
(10.72)\end{array}$ & $\begin{array}{c}11.48 \\
(11.28)\end{array}$ & $\begin{array}{l}\text { greenish } \\
\text { yellow }\end{array}$ & 78 & $262-3$ \\
\hline GL2C & $\mathrm{C}_{26} \mathrm{H}_{23} \mathrm{CoN}_{4} \mathrm{O}_{4}$ & 522.4 & $\begin{array}{c}59.81 \\
(59.78) \\
\end{array}$ & $\begin{array}{c}4.76 \\
(4.25) \\
\end{array}$ & $\begin{array}{c}10.35 \\
(10.72) \\
\end{array}$ & $\begin{array}{c}11.66 \\
(11.28) \\
\end{array}$ & $\begin{array}{l}\text { greenish } \\
\text { yellow }\end{array}$ & 77 & $262-3$ \\
\hline
\end{tabular}

The elemental analysis data of the Schiff bases and the cobalt complexes are consistent with the proposed stoichiometry as shown in Table 2 . The proposed structures of the Schiff bases and the cobalt complexes were identified using elemental analysis, mid- and far-infrared, UV-vis in methanol, diffused reflectance. ${ }^{1} \mathrm{H}$ NMR and ${ }^{13} \mathrm{C}$ NMR were further used to characterized the Schiff bases. The GL1 and GL2 with their corresponding cobalt complexes gave a sharp melting point indicating the isolation of fairly pure Schiff bases and complexes. The microanalysis analysis for $\mathrm{C}, \mathrm{H}, \mathrm{N}$ and $\mathrm{O}$ as well as the molecular weight of the complexes obtained were in agreement with the predicted formula for the Schiff bases and complexes. An outline of the proposed structure for GL1 and GL2 are depicted in Schemes 1.
${ }^{1} \mathrm{H}$ NMR spectra and ${ }^{13} \mathrm{C}$ NMR spectra

The diagnostic NMR spectra data for GL1 and GL2 are listed in Table 3. The observed spectra showed signals in the $\delta 7.2-8.6(\mathrm{~m})$ region for the aromatic protons. The formation of the GL1 and GL2 is confirmed by the presence of $\mathrm{C}=\mathrm{N}$ azomethine proton signal appearance at $\delta 8.47$ ppm and $\delta 8.65$ ppm respectively (Bilge, Kiliç, Hayvali, Hökelek \& Serap, 2009). Singlet signals appearance at $\delta 3.78$ and $3.94 \mathrm{ppm}$ are attributed to the para and meta-methoxy protons for GL1 and GL2 respectively. The chemical shifts at 13.13 ppm and 13.09 ppm implies the predominance of enol-imine tautomer (Nazir, et al., 2000). All the carbon peaks were observed in the ${ }^{13} \mathrm{C}$ NMR at the expected positions. The structures of the Schiff bases were also confirmed by sharp signals of ${ }^{13} \mathrm{C}$ NMR spectra. 
Table 3:1H and 13C chemical shift of GL1 and GL2

\begin{tabular}{llllll}
\hline No. & Schiff base & & $\underline{\mathrm{HC}}=\mathrm{N}$ & $\mathrm{C}-\mathrm{O} \underline{\mathrm{H}}$ & $\mathrm{O}-\mathrm{C}_{3}$ \\
\hline 1 & GL1 & ${ }^{1} \mathrm{H}$ & $8.47(\mathrm{~s}, 1 \mathrm{H})$ & $13.13(\mathrm{~s}, 1 \mathrm{H})$ & $3.78(\mathrm{~s}, 3 \mathrm{H})$ \\
& & ${ }^{13} \mathrm{C}$ & 163.6 & 164.4 & 55.5 \\
2 & \multirow{2}{*}{$\mathrm{GL} 2$} & ${ }^{1} \mathrm{H}$ & $8.65(\mathrm{~s}, 1 \mathrm{H})$ & $1309(\mathrm{~s}, 1 \mathrm{H})$ & $3.94(\mathrm{~s}, 3 \mathrm{H})$ \\
& & ${ }^{13} \mathrm{C}$ & 164.6 & 151.2 & 56.2
\end{tabular}

FTIR spectra

The important infra-red data of the Schiff bases, GL1, GL2 and the cobalt complexes are given in Table 4. The mid IR and far IR spectra of the Schiff bases and their cobalt (II) complexes provide information about the cobalt-Schiff base bonding. The FTIR spectra data of GL1, GL2 and their isolated cobalt complexes are listed in Table 4. The main stretching frequencies and their assignments are listed in Table 4. The formation of the Schiff base GL1 and GL2 is supported by the appearance of a strong band at 1610 and 1615 $\mathrm{cm}^{-1}$ due to $\nu(\mathrm{C}=\mathrm{N})_{\text {(imine) }}$ in the IR spectra of these Schiff base (Yeap, Ha, Ishizawa \& Suda, 2003). The Schiff bases exhibit a broad band centred at $3442 \mathrm{~cm}^{-1}$. This suggests the involvement of the 3$\mathrm{OH}$ or $4-\mathrm{OH}$ group in the intramolecular hydrogen bonding with the lone pair of azomethine nitrogen (Maurya, Jaiswal \& Verma, 1998). It also suggests that the Schiff bases GL1 and GL2 exist in enol form in the solid state (Maurya, Chourasia \& Sharma, 2008).

In order to ascertain the bonding modes of the bidentate GL1 and GL2 to the cobalt metal, the vibrations of the GL1, GL2 were compared with their corresponding cobalt (II) complexes. The IR spectra vibration observed at $1610 \mathrm{~cm}^{-1}$ and 1615 $\mathrm{cm}^{-1}$ for GL1 and GL2 assigned to $\nu(\mathrm{C}=\mathrm{N})_{\text {(imne) }}$ shifted to higher wavenumber in GL1B, GL1C, but shifted to lower wavenumber in GL1A suggesting coordination through $\mathrm{N}$ atom of the azomethine (Sliverstein, Bassler \& Morrill, 2005; Tyagi, Chandra and Tyagi, 2014). Similarly, the vibrations of GL2A, GL2B and GL2C appeared at lower wavenumber relative to GL2. Another diagnostic vibration is the C-O stretching frequencies which occur at $1297 \mathrm{~cm}^{-1}$ and $1259 \mathrm{~cm}$ ${ }^{1}$ in GL1 and GL2 respectively. The $\nu(\mathrm{C}=\mathrm{O})_{\text {(imne) }}$ stretching frequencies of the complexes appeared at lower wavenumber. A medium band observed in the region between $3442-3438 \mathrm{~cm}^{-1}$ due to $\mathrm{O}-\mathrm{H}$ stretching modes are indicative of lattice water (Singh et al., 2002). In addition, two weaker bands in the region 755-795 and 702-718 $\mathrm{cm}^{-1}$ are attributed to $\mathrm{Co}(-\mathrm{OH})$ rocking and wagging mode of vibrations, respectively (Ejidike and Ajibade, 2015). The band which appeared at approximately $1578 \mathrm{~cm}^{-1}$ assigned to $v(\mathrm{C}=\mathrm{N})$ of the pyridine moiety shifted to higher frequencies in the spectra of the complexes (Abd-elzaher, 2004). This shift suggests that the nitrogen of the pyridine participated in the formation of the complex.

Table 4: Mid and far Infrared frequencies (cm-1) of the GL1, GL2 and their cobalt complexes

\begin{tabular}{|c|c|c|c|c|c|c|c|c|c|c|}
\hline & $\nu \mathrm{O}-\mathrm{H}$ & $\nu \mathrm{C}=\mathbf{N}_{(\mathrm{imne})}$ & $\nu C=N_{(p y)}$ & $\nu \mathrm{C}-\mathrm{O}$ & $v_{\mathrm{a}} \mathrm{M}-\mathrm{O}$ & $v_{s} \mathrm{M}-\mathrm{O}$ & $v_{\mathrm{a}} \mathrm{M}-\mathrm{N}$ & $v_{s} \mathbf{M}-\mathbf{N}$ & \multicolumn{2}{|c|}{ other } \\
\hline GL1 & 3442 & 1610 & 1586 & 1297 & - & - & - & - & - & - \\
\hline GL1A & 3441 & 1609 & 1568 & 1207 & 591, 572 & 545 & $\begin{array}{l}497 \\
430\end{array}$ & $\begin{array}{l}413, \\
393\end{array}$ & 340 & 366 \\
\hline GL1B & 3440 & 1615 & 1574 & 1210 & 576 & 521 & 496 & 409 & - & $\begin{array}{r}365 \\
318\end{array}$ \\
\hline GL1C & 3438 & 1615 & 1575 & 1211 & 576 & 520 & 496 & 409 & - & $\begin{array}{r}364, \\
318\end{array}$ \\
\hline GL2 & 3440 & 1615 & 1565 & 1259 & - & - & - & - & - & - \\
\hline GL2A & 3439 & 1608 & 1541 & 1235 & 566 & 530 & 494 & 447 & 255 & 287 \\
\hline GL2B & 3441 & 1614 & 1539 & 1234 & 541 & 520 & 470 & 347 & 271 & - \\
\hline GL2C & 3442 & 1614 & 1563 & 1245 & 546 & 523 & 478 & 350 & 278 & - \\
\hline
\end{tabular}


The coordination of cobalt to the GL1 and GL2 is also confirmed by the appearance of new bands in the spectra of the metal complexes in the far infrared region. The stretching of cobalt-oxygen and cobalt-nitrogen bands of the complexes appeared in the lower wavelength region in the range of $591-520 \mathrm{~cm}^{-1}$ and $498-347 \mathrm{~cm}^{-1}$ also signifying the complexation through oxygen and imine or pyridine nitrogen atoms from the ligand (Nakamoto, 1997). The appearance of medium bands at the range of $498-347 \mathrm{~cm}^{-1}$ is attributed to the $\nu_{\text {assm }}$ and $v_{\text {sym }}(M-N)$ bond (Abdallah \& Zayed, 2010). The big difference between the asymmetry and the symmetry of the $\mathrm{M}-\mathrm{N}$ vibration might be an indication of high covalent character. In addition, the stretching frequencies in the range of $591-520 \mathrm{~cm}^{-1}$ are attributed to the $v_{\text {assm }}$ and $v_{\text {sym }}$ cobalt-oxygen bond formation (Tyagi et al., 2014). In addition, a band at 305 is assigned to the $v(\mathrm{M}$ $\mathrm{Cl}$ ). Thus the IR spectral data results provide strong evidences for the complexation of the bidentate GL1 and GL2 Schiff bases and also suggests that the cobalt(II) coordinated through azomethine or pyridine nitrogen and through oxygen of the aromatic ring.

\section{Electronic Spectra}

The important electronic spectra data of the Schiff bases GL1, GL2 and their complexes in

methanol are listed in Table 5 . The various bands are grouped into range between $210-245 \mathrm{~nm}, 280$ $290 \mathrm{~nm}, 302-372 \mathrm{~nm}$ and $421 \mathrm{~nm}$. The first and the second bands are attributed to benzene $\pi-\pi^{*}$, the third is attributed to imino $\pi-\pi^{*}$ transitions while the band above $400 \mathrm{~nm}$ shown by these Schiff bases is attributed to imino $n-\pi^{*}$ transition (Canpolat \& Kaya, 2004). The appearance of the band above $400 \mathrm{~nm}$ implies significant quantity of keto-amine tautomer of the Schiff bases in methanol. The complexes showed similar electronic transitions as observed in the Schiff bases GL1 and GL2. However, the transition of the complexes shifted towards higher wavelengths or lower energy. The shift is position of the methoxy or type of cobalt salt used dependent. The cobalt chloride-based complexes of GL1 in methanol, shows maxima at about 360, 285, 240 and 205 while the cobalt acetate-based complexes show maxima at slightly higher wavelengths. Interestingly, the GL2 complexes appeared at much higher wavelengths than the GL1 complexes. All the observed maxima are attributed to charge transfer bands. The shift maybe attributed to the donation of the lone pairs of the nitrogen atom $(\mathrm{N} \rightarrow \mathrm{M})$ or the $(\mathrm{O} \rightarrow \mathrm{M})$ of the Schiff bases to the metal ion. The d-d bands were not seen or too low to be seen.

Table 5: Electronic spectra data $(\mathrm{nm})$ in $3.0 \times 10^{-3} \mathrm{~mol} \mathrm{dm}^{-3}$, diffuse reflectance and brine shrimps lethality data for GL1, GL2 and their cobalt(II) complexes

\begin{tabular}{|c|c|c|c|c|c|c|c|c|c|c|}
\hline & \multicolumn{6}{|c|}{ Methanol $3.0 \times 10^{-3} \mathrm{~mol} \mathrm{dm}^{-3}(\mathrm{~nm})$} & Diffuse reflectance (nm) & LD50 & Standard error & Pseudo R \\
\hline GL1 & 210 & 225 & 245 & 285 & & & & 4.30 & 0.06 & 0.980 \\
\hline GL1A & 205 & & 240 & 285 & - & 360 & $366,583,625,1400-1200$ & 4.25 & 0.11 & 0.900 \\
\hline GL1B & & & & 280 & 338 & 373 & & 5.47 & 0.12 & 0.991 \\
\hline GL1C & 207 & - & & 275 & - & 377 & & 5.21 & 0.12 & 0.988 \\
\hline GL2 & & 225 & & 275 & - & 416 & & 4.49 & 0.04 & 0.930 \\
\hline GL2A & 211 & & 240 & 270 & 285 & $391-$ & $389,582,636,1400-1200$ & 4.46 & 0.14 & 0.906 \\
\hline GL2B & 205 & & 245 & 280 & 335 & 401 & & 3.96 & 0.17 & 0.889 \\
\hline GL2C & 205 & & 241 & 279 & - & 400 & & 5.62 & 0.08 & 0.913 \\
\hline
\end{tabular}

However, in order to further characterize the complexes, the diffused reflectance technique was used to examine them in the UV-vis and the NIR$\mathrm{UV}$-vis regions. The spectra of the complexes are illustrated in Figures 1 and 2 respectively. On the basis of their diffused reflectance spectra, the cobalt complexes can be classified as tetrahedral because their spectra show absorption bands at 1400-1200, 600-500, and slightly below $400 \mathrm{~nm}$ (Ashmawy \& Amer, 1986). The band at 1400-1200 nm can be assigned to low symmetry components of the second tetrahedral transizion ${ }^{4} \mathrm{~A}_{2}{ }^{4} \mathrm{~T}_{1}(\mathrm{~F})$. The band at 600-500 $\mathrm{nm}$ is assigned to $\rightarrow$ he ${ }^{4} \mathrm{~A}_{2}$ ${ }^{4} \mathrm{~T}_{1}(\mathrm{P})$ transition. However, while the bands for the cobalt acetate or cobalt chloride with triethylamine of the complexes are similar, they have lower intensity that are not well resolved like those of cobalt chloride GL1A, GL2A. However, we still suggest distorted tetrahedral coordination 
for the GL1B, GL1C, GL2B, GL2C complexes. The result confirms that the four - coordinate tetrahedral and the six - coordinate octahedral are the idealized geometries for few, if any complexes have been shown to attain symmetry high enough to be called tetrahedral or octahedral in the group theoretical sense (Carlin, 1965).

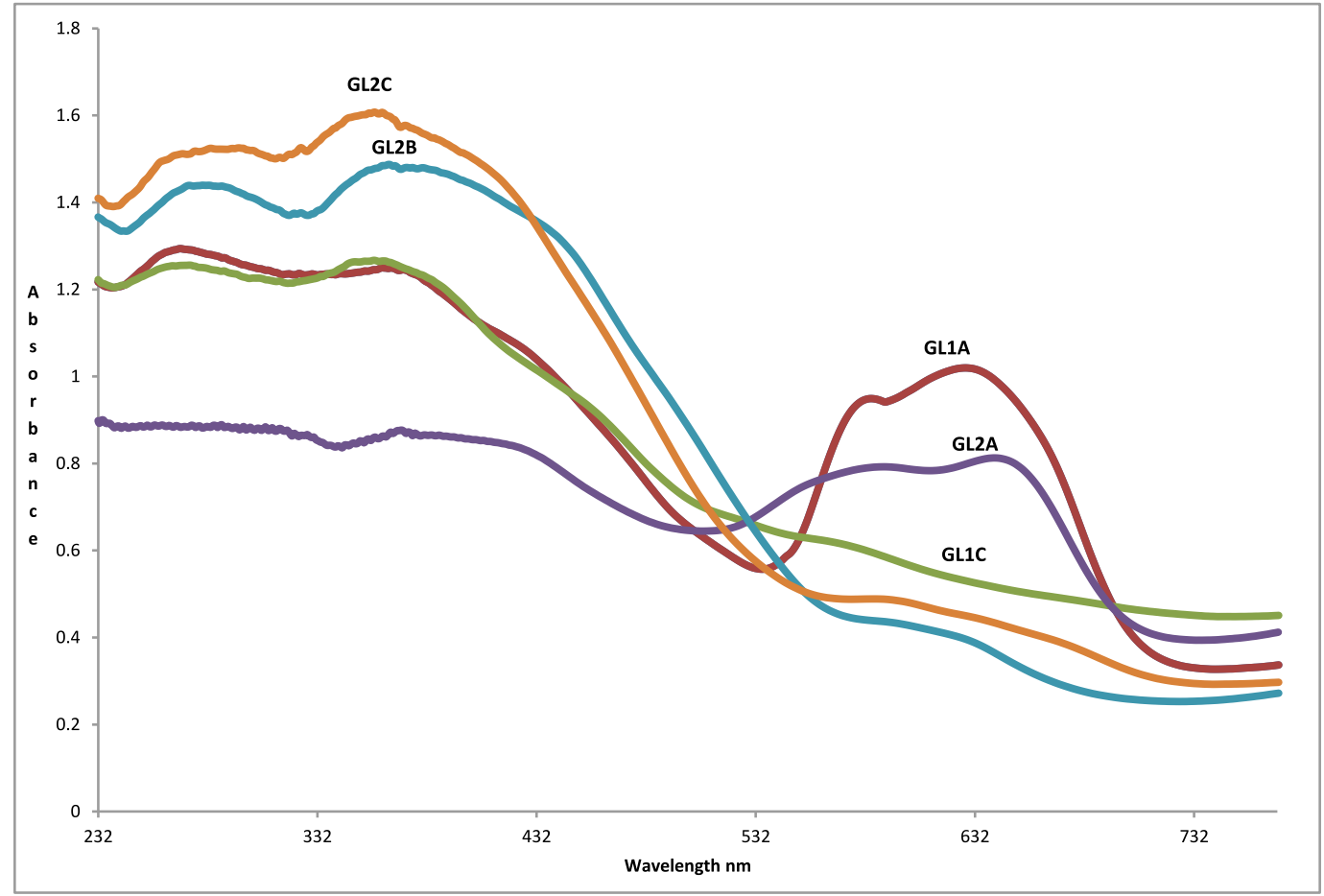

Figure 1: Diffused reflectance spectra of cobalt complexes in the UV-vis region

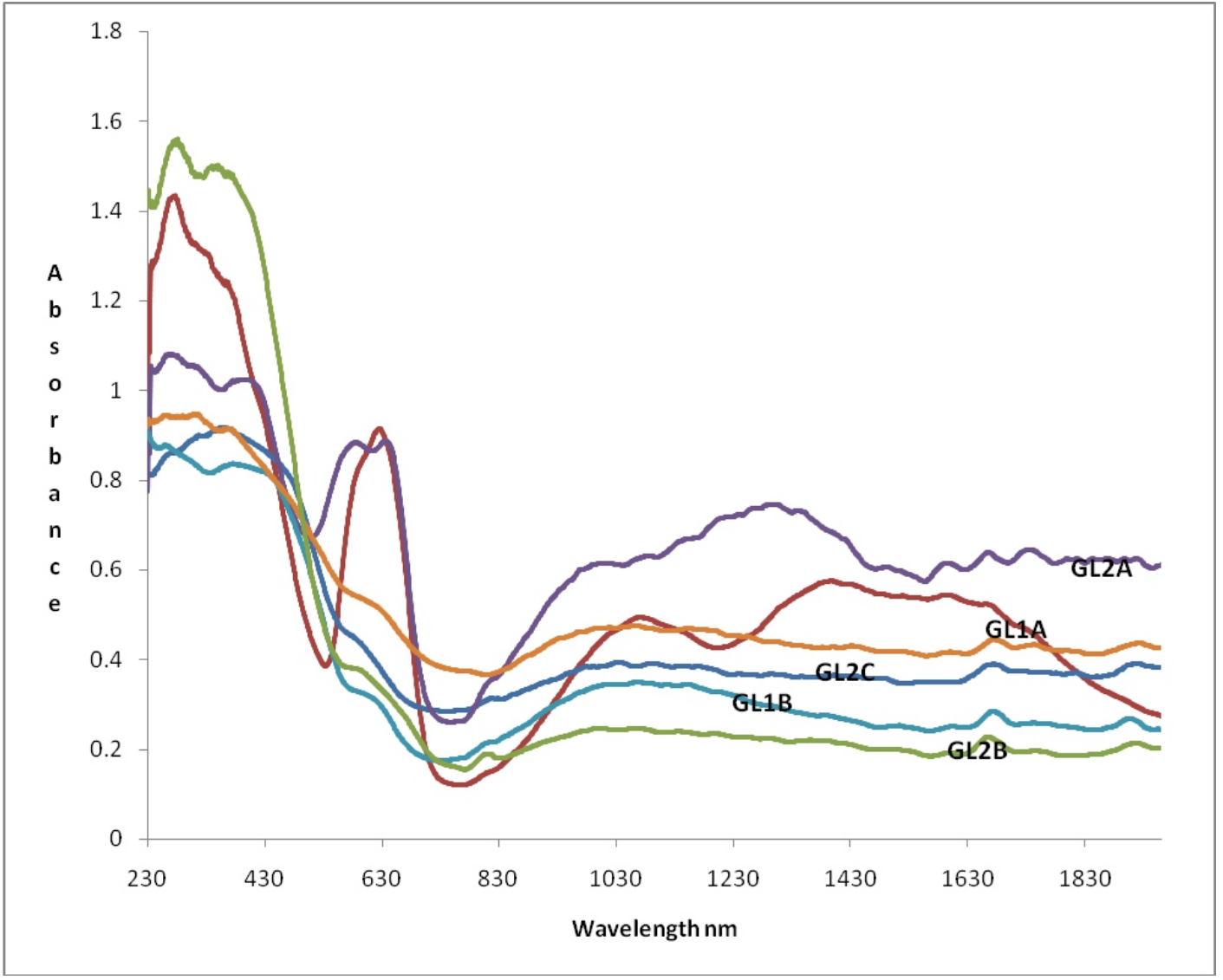

Figure 2: Diffused reflectance spectra of cobalt complexes in the NIR-Uv-vis region 


\section{Biological Activities}

Antimicrobial Activity

The free Schiff bases GL1, GL2 and GL1A, GL1B, GL2A, GL2B complexes were tested for their in vitro antibacterial activity against the bacterial species Staphylococcus Aureus, Pseudomonas aeruginosa, Escherichia coli and fungus, Aspergillus niger. by zone of inhibition method using agar diffusion method (Frankle et al., 1970; Yousif et al., 2017). The comparison of the biological activities of the synthesized Schiff bases and their complexes shows the following results. Cobalt complex of GL1 showed broad range of antimicrobial activity against all the tested microorganism more than the other complexes. The cobalt chloride-based complex GL1A is more active than the GL1B and GL1C complexes. Generally, varying toxicity of the chelated compounds and the Schiff bases against the tested microorganism were observed and toxicity is concentration dependent. The strong activity of most of the complexes with the two Schiff bases against E. coli and Pseudomonas aeruginosa (Gram-negative bacteria) and Aspergillus niger is well observed. This is attributed to their ability to combine with the lipophilic layer in order to enhance the membrane permeability of the Gram-negative bacteria. The increase in lipophilicity enhances the penetration of GL1, GL2 and their synthesized cobalt complexes into the lipid membranes and thus restricts further growth of the organism (Raman et al., 2009; Maldonadol et al., 1995; Tumer et al., 1999; Imran et al., 2007). Although there is sufficient increase in the antibacterial activity of the complexes as well as the Schiff bases, they could not fully reach the effectiveness of the standard drug, ampicillin, but more active than the antifungal drug used. The toxicity of GL1 and its complexes on $S$. aureus are more than those of GL2 and its complexes. This may imply that the presence of $\mathrm{OCH}_{3}$ group in the para position imparted high interaction with the double membrane of the $S$. aureus than the metamethoxy (Mohamed, Zayed, \& Abdallah, 2010). The less activity of some of the compounds against microorganism can be ascribed to the creation of alternative pathways that have been modified by the microorganism to get a way around so as to survive the effect of the drugs (Yeaman \& Yount, 2003).

\section{Brine Shrimps Lethality Test}

The brine shrimp lethality test was employed in this study to determine the toxicity of the various Schiff bases and their cobalt(II) complexes, hoping to find a correlation between this assay and cytotoxicity (Meyer et al., 1982). The $\mathrm{LD}_{50}$ values of the synthesized compounds are listed in Table 5. The test samples showed different mortality rate at different concentration on the brine shrimps. The activities are concentration and geometry dependent. GL2B appeared to be the most toxic to the brine shrimps because it has the lowest $\mathrm{LD}_{50}$ value.

\section{CONCLUSION}

In the present study, two novel Schiff bases and six cobalt complexes were synthesized and characterized by physico-chemical methods. The cobalt ions were complexed with nitrogen of the imine or pyridine and $\mathrm{C}-\mathrm{O}$ producing distorted tetrahedral geometry complexes. The antibacterial and antifungal data given for the compounds presented in this study showed that the metal complexes generally have better activity than Schiff bases GL1, GL2 and less activity than antibacterial standard but better activity than the antifungal drugs used.

\section{ACKNOWLEDGEMENT}

The authors gratefully acknowledge the Joint Research Committee of Rhodes University for granting financial support and the Department of Chemistry, Rhodes University, South Africa, for granting the laboratory space.

\section{REFERENCES}

Abd-elzaher, M. M. (2004). Synthesis and Spectroscopic Characterization of Some Ferrocenyl Schiff Bases Containing Pyridine Moiety and Their Complexation with Cobalt, Nickel, Copper and Zinc. Journal of the Chinese Chemical Society, 51, 499-504.

Abdallah, S. M., \& Zayed, M. A. (2010). Synthesis and spectroscopic characterization of new tetradentate Schiff base and its coordination compounds of NOON 
donor atoms and their antibacterial and antifungal activity. Arabian Journal of Chemistry, 3(2), 103-113. https://doi.org/10.1016/j.arabjc.2010.02 .006

Anderson, J. E., Goetz, C. M., \& McLaughlin, J. L. (1991). Phytochem. Analys. Phytochem. Analys., 107-111.

Ashmawy, F. M., \& Amer, S. A. (1986). Synthesis and Characterisation of Some Cobalt(ii) Complexes of Schiff-base Ligands and Their Reactions with Molecular Oxygen. Effects of Chelate Ring Size. J. CHEM. SOC. DALTON TRANS., 421-426.

Atkins, R., Brewer, G., Kokot, E., Mockler, G. M., \& Sinn, E. (1985). Copper(I1) and Nickel(I1) Complexes of Unsymmetrical Tetradentate Schiff Base Ligands. Inorganic Chemistry, 24(2), 127-134.

Bhattacharyya, A., Sen, S., Harms, K., \& Chattopadhyay, S. (2015). Formation of three photoluminescent zinc (II) complexes with $\mathrm{Zn} 2 \mathrm{O} 2$ cores: Examples of bi-dentate bonding modes of potentially tri- and tetra-dentate Schiff bases. POLYHEDRON, 88, 156-163. https://doi.org/10.1016/j.poly.2014.12.0 18

Bilge, S., Kiliç, Z., Hayvali, Z., Hökelek, T., \& Serap, S. (2009). Intramolecular hydrogen bonding and tautomerism in Schiff bases: Part VI. Syntheses and structural investigation of salicylaldimine and naphthaldimine derivatives. J. Chem. Sci. 121(6), 989-1001.

Boucher, L. J., \& Coe, C. G. (1976). Manganese Schiff Base Complexes. 7. Synthesis and Circular Dichroism of Optically Active Tetradentate Chelates of Manganese(III) and of $\mu$-Oxo- $\mu$-hydroxodimanganese(III,IV) Dimers. Inorganic Chemistry, 15(6), 1334-1340. https://doi.org/10.1021/ic50160a018

Canpolat, E., \& Kaya, M. (2004). Studies on mononuclear chelates derived from substituted Schiff- base ligands (part 2): synthesis and characterization of a new 5bromosalicyliden- p - amino acetophenoneoxime and its complexes with $\mathrm{Co}$ (II), $\mathrm{Ni}$ (II), $\mathrm{Cu}$ (II) and $\mathrm{Zn}$ (II). J.
Coord. Chem., 57, 1217-1223. https://doi.org/10.1080/009589704123 31285913

Carlin, R. L. (1965). Stereochemistry of cobalt(II) in transition metal chemistry, A series of advances vol. 1 (London, Ma). New York.: Inc., Edward Arnold (Publisher) Ltd.

Cui, Y., Dong, X., Li, Y., Li, Z., \& Chen, W. (2012). Synthesis, structures and urease inhibition studies of Schiff base metal complexes derived from 3,5-dibromosalicylaldehyde. European Journal of Medicinal Chemistry, 58, 323-331. https://doi.org/10.1016/ j.ejmech.2012.09.037

Ejidike, I. P., \& Ajibade, P. A. (2016). of Ru (III) Complexes of Monobasic Tridentate Schiff Bases, 2016.

Elmali, A., Zeyrek, C. T., Elerman, Y., \& Durlu, T. N. (2000). Structures of four- and sixcoordinate monomers of $[\mathrm{N}, \mathrm{N} \square$ - bis (5chlorosalicylidene) -1, 3-diaminopropane] nickel (II). J. Chemical Crystallography, 30(3), 167-171. https://doi.org/doi.org /10.1023/A:1009526913565

Ernst, E. J., \& Rogers, P. D. (2005). Antifungal agents methods and protocols. Totowa, New Jersey: Human Press.

Finney, D. J. (1971). Probit analysis (3rd ed.). Cambridge.: Cambridge University Press.

Frankle, S. Reitman, S. Sonnenwir, A. (1970). Clinical Laboratory Method and Diagnosis (7th ed.). Germany: C.V. Mosby Co.

Furst, A. (1963). The Chemistry of Chelation in Cancer. (3rd ed.). Thomas: Spring- field.

Gurumoorthy, P., Mahendiran, D., Parbhu, D., Arulvasu, C., \& Rahiman, A. K. (2014). Magneto-structural correlation, antioxidant, DNA interaction and growth inhibition activities of new chlorobridged phenolate complexes Perumal. RSC Adv. 4, 42855-42872. https://doi.org/10.1039/b000000x

Hania, M. M. (2009). Synthesis and Antibacterial Activity of Some Transition Metal Complexes of Oxime, Semicarbazone and Phenylhydrazone. E-Journal of Chemistry 6(Ii), S508-S514. https://doi.org/10.1155/2009/204714 
Hegazy, W. H., \& Gaafar, A. E. D. M. (2012). Synthesis, Characterization and antibacterial activities of new Pd(II) and $\mathrm{Pt}(\mathrm{IV})$ complexes of some unsymmetrical tetradentate Schiff bases. American Chemical Science Journal 2(3), 86-99. https://doi.org/10.9734/ACSJ/2012/15 84

Imran, M., Iqbal, J., Iqbal, S., \& Ijaz, N. (2007). In Vitro Antibacterial Studies of Ciprofloxacin-imines and Their Complexes with $\mathrm{Cu}$ (II), Ni (II), Co (II), and Zn (II). Turk J. Biol. 31, 67-72.

Jain, S., Jain, N. K., \& Pitre, K. S. (2002). Electrochemical analysis of sparfloxacin in pharmaceutical formulation and biochemical screening of its Co(II) complex. Journal of Pharmaceutical and Biomedical Analysis 29(5), 795-801. https:// doi.org/10.1016/S07317085(02)00178-4

Madigan, M. T., Martinko, J. M., \& Parker, J. (1998). Biology of microorganism (8th ed). New York: Upper Saddle River, Prentice Hall.

Maldonadol, J., Rathelotl, P., Vanelle, P., Gasquetz, M., Delmas, F., Crozet, M. P., \& TimonDavid, P. (1995). Synthesis of novel functionalized 5nitroisoquinolines and evaluation of in vitro antimalarial activity. Eur JMed Chem 30, 503-508.

Maurya, R. C., Chourasia, J., \& Sharma, P. (2008). Bis(o-vanillin)benzidine(o-v2bzH2) as a binucleating ligand: Synthesis, characterization and 3D molecular modeling and analysis of some binuclear complexes of o-v2bzH2 with copper(II), nickel(II), cobalt(II), manganese(II), zinc(II), samarium(III) and dio. Indian Journal of Chemistry 47(April), 517-528.

Maurya, R. C., Jaiswal, M. N., \& Verma, R. (1998). The Coordination Chemistry of Dioxouranium (VI): Studies on Some Novel Di- and Trinuclear Dioxouranium ( VI ) Complexes with Pyrazolone Based Schiff Bases. SYNTH. REACT. INORG. MET.-ORG. CHEM. 28(8), 1265-1281. https://doi.org/10.1080/009457198093 49404

Meyer, B. N., Ferrigni, N. A., Putnam, J. E.,
Jacobsen, L. B., Nichols, D. E., \& Mclaughlin, J. L. (1982). Brine Shrimp: A Convenient General Bioassay for Active Plant Constituents. Journal of Medicinal Plant Research 45, 31-34.

Mohamed, G. G., Zayed, M. A., \& Abdallah, S. M. (2010). Metal complexes of a novel Schiff base derived from sulphametrole and varelaldehyde. Synthesis, spectral, thermal characterization and biological activity. Journal of Molecular Structure 979, 627 https://doi.org/10.1016/j.molstruc.2010 .06 .002

Nakamoto, K. (1997). Infrared of Inorganic and Coordination Compounds (6th ed). New York:John-Wiley.

Nazir, H. Yildiz, M. Yilmaz, H. Tahir N. Ulku, D. (2000). Intramolecular hydrogen bonding and tautomerism in Schiff bases. Structure of N - (2-pyridil) -2-oxo-1naphthylidenemethylamine. J. Molecular Structure 524, 241-250.

R Data. (2000). Data analysis software.

Raman, N., Raja, Johnson, S., \& Sakthivel, A. (2009). Transition metal complexes with Schiff- base ligands?: 4-aminoantipyrine based derivatives - a review. Journal of Coordination Chemistry 62(5), 691-709. https://doi.org/10.1080/009589708023 26179

Saxena, A. (1987). Organotin compounds: toxicology and biomedicinal applications. Applied Organometallic Chemistry 1(1), 39-56.

Singh, G. Singh, P. A Singh,K. Singh, D. P. Handa,R. N. Dubey, S. N. (2002). Synthesis and structural studies of some bivalent metal complexes with bidentate Schiff base ligands. Proceedings of National Academy of Sciences India 72(A-2), 87-95.

Sliverstein, R., Bassler, G., \& Morrill, T. (2005). Spectrometric Identification of Organic Compound (7th ed.). New York: JohnWiley.

Soliman, A. A., \& Linert, W. (1999). Investigations on new transition metal chelates of the 3methoxy-salicylidene-2-aminothiophenol Schiff base. Thermochimica Acta 338, 
67-75. https://doi.org/10.1016/S00406031(99)00201-4

Tumer, M., Sener, M. K., Serin, S., \& Koksal, H. (1999). Antimicrobial activity studies of the binuclear metal complexes derived from tridentate Schi base ligands. Transition Met. Chem. 24, 414-420.

Tyagi, M., Chandra, S., \& Tyagi, P. (2014). Spectrochimica Acta Part A: Molecular and Biomolecular Spectroscopy Mn (II) and $\mathrm{Cu}$ (II) complexes of a bidentate Schiff ' s base ligand: Spectral, thermal, molecular modelling and mycological studies. SPECTROCHIMICA ACTA PART A: MOLECULAR AND BIOMOLECULAR SPECTROSCOPY 117, 1-8. https://doi.org/10.1016 /j.saa.2013.07.074

Williams, D. R. (1972). Thermodynamic considerations in co-ordination. Part X. A potentiometric and calorimetric investigation of copper(II) histidine complexes in solution. Journal of the Chemical Society. Dalton Transactions. 7,790-797.

Yeaman, M. R., \& Yount, N. Y. (2003). Mechanisms of Antimicrobial Peptide Action and Resistance. Pharmacological Reviews, 55(1), 27-55. https:// doi.org/10.1124/pr.55.1.2.27
Yeap, G., Ha, S., Ishizawa, N., \& Suda, K. (2003). Synthesis, crystal structure and spectroscopic study of para substituted 2hydroxy-3-methoxybenzalideneanilines, 658, 87-99. https://doi.org/ 10.1016/S0022-2860(03)00453-8

Yousif, E., Majeed, A., Al-sammarrae, K., Salih, N., Salimon, J., \& Abdullah, B. (2017). Metal complexes of Schiff base: Preparation, characterization and antibacterial activity. Arabian Journal of Chemistry 10, S1639-S1644. https:// doi.org/10.1016/j.arabjc.2013.06.006

Yuan Ruo, Chai Ya-Qin, Liu Dong, Gao De, Li Jun-Zhong, Y. R.-Q. (1993). Schiff Base Complexes of Cobalt(II) as Neutral Carriers for Highly Selective Idodide Electrodes. Anal. Chem 65(19), 25722575.

Zolezzi, S., Decinti, A., \& Spodine, E. (1999). Syntheses and characterization of copper (II) complexes with Schiff-base ligands derived from ethylenediamine, diphenylethylenediamine and nitro, bromo and methoxy salicylaldehyde. POLYHEDRON 18, 897-904. https:// doi.org/10.1016/S0277-5387(98)003763 